\title{
Oral administration of repurposed drug targeting Cyp46A1 increases survival times of prion infected mice
}

\author{
Tahir Ali ${ }^{1,2}$, Samia Hannaoui ${ }^{1,2}$, Satish Nemani ${ }^{3}$, Waqas Tahir ${ }^{1,2}$, Irina Zemlyankina ${ }^{1,2}$, Pearl Cherry ${ }^{1,2}$, \\ Su Yeon Shim ${ }^{1,2}$, Valerie Sim ${ }^{3}$, Hermann M. Schaetzl ${ }^{1,2}$ and Sabine Gilch ${ }^{1,2^{*}}$ (1)
}

\begin{abstract}
Prion diseases are fatal, infectious, and incurable neurodegenerative disorders caused by misfolding of the cellular prion protein $\left(\mathrm{PrPC}^{\mathrm{C}}\right)$ into the infectious isoform $\left(\mathrm{PrP}^{\mathrm{SC}}\right)$. In humans, there are sporadic, genetic and infectious etiologies, with sporadic Creutzfeldt-Jakob disease (sCJD) being the most common form. Currently, no treatment is available for prion diseases. Cellular cholesterol is known to impact prion conversion, which in turn results in an accumulation of cholesterol in prion-infected neurons. The major elimination of brain cholesterol is achieved by the brain specific enzyme, cholesterol 24-hydroxylase (CYP46A1). Cyp46A1 converts cholesterol into 24(S)-hydroxycholesterol, a membrane-permeable molecule that exits the brain. We have demonstrated for the first time that Cyp46A1 levels are reduced in the brains of prion-infected mice at advanced disease stage, in prion-infected neuronal cells and in post-mortem brains of SCJD patients. We have employed the Cyp46A1 activator efavirenz (EFV) for treatment of prion-infected neuronal cells and mice. EFV is an FDA approved anti-HIV medication effectively crossing the blood brain barrier and has been used for decades to chronically treat HIV patients. EFV significantly mitigated PrPSC propagation in prion-infected cells while preserving physiological PrPC and lipid raft integrity. Notably, oral administration of EFV treatment chronically at very low dosage starting weeks to months after intracerebral prion inoculation of mice significantly prolonged the lifespan of animals. In summary, our results suggest that Cyp46A1 as a novel therapeutic target and that its activation through repurposing the anti-retroviral medication EFV might be valuable treatment approach for prion diseases.
\end{abstract}

\section{Introduction}

Prion diseases, or transmissible spongiform encephalopathies (TSEs), are a group of devastating, infectious and fatal neurodegenerative disorders caused by proteinaceous infectious pathogens termed as prions. Prion diseases affect both humans and animals. The human prion diseases include sporadic Creutzfeldt-Jakob disease $(\mathrm{sCJD})$ as the most common form, genetic forms

\footnotetext{
*Correspondence: sgilch@ucalgary.ca

${ }^{1}$ Calgary Prion Research Unit, Department of Comparative Biology and Experimental Medicine, Faculty of Veterinary Medicine, University of Calgary, 3330 Hospital Drive NW, Calgary, AB T2N 4Z6, Canada Full list of author information is available at the end of the article
}

(e.g. Gerstmann-Sträussler-Scheinker syndrome (GSS) and fatal familial insomnia (FFI)) and acquired forms such as iatrogenic CJD (iCJD) and variant CJD (vCJD). Animal prion diseases include scrapie in sheep, bovine spongiform encephalopathy (BSE) in cattle, and chronic wasting disease (CWD) in cervids (elk, mule deer, whitetailed deer, moose and reindeer) [1-5]. The possibility of zoonotic transmission as demonstrated by BSE and the resulting $\mathrm{vCJD}$, and the unknown potential of CWD to cross the species barrier to humans impose a challenge especially in the absence of therapeutics. Therefore, it is of paramount importance to identify new drug

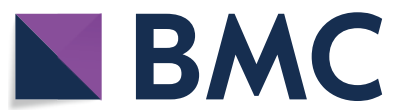

(c) The Author(s) 2021. Open Access This article is licensed under a Creative Commons Attribution 4.0 International License, which permits use, sharing, adaptation, distribution and reproduction in any medium or format, as long as you give appropriate credit to the original author(s) and the source, provide a link to the Creative Commons licence, and indicate if changes were made. The images or other third party material in this article are included in the article's Creative Commons licence, unless indicated otherwise in a credit line to the material. If material is not included in the article's Creative Commons licence and your intended use is not permitted by statutory regulation or exceeds the permitted use, you will need to obtain permission directly from the copyright holder. To view a copy of this licence, visit http://creativecommons.org/licenses/by/4.0/. The Creative Commons Public Domain Dedication waiver (http://creativeco mmons.org/publicdomain/zero/1.0/) applies to the data made available in this article, unless otherwise stated in a credit line to the data. 
targets and novel therapeutic approaches to treating prion disease.

Prion diseases are caused by the conversion of the cellular prion protein $\left(\mathrm{PrP}^{\mathrm{C}}\right)$ into an infectious and misfolded isoform known as $\operatorname{PrP}^{\mathrm{Sc}}$. $\operatorname{PrP}^{\mathrm{C}}$ is rich in alpha-helices and sensitive to proteases, while $\operatorname{PrP}^{\mathrm{Sc}}$ consists mostly of betasheets, is prone to aggregate and partially resistant to proteases. Its accumulation in the central nervous system leads to vacuolization and progressive neurodegeneration [6-8]. The mechanism of prion conversion is mostly enigmatic but occurs upon direct interaction of $\operatorname{PrP}^{\mathrm{Sc}}$ with $\operatorname{PrP}^{\mathrm{C}}$ which induces the conformational changes. On a subcellular level, prion conversion is thought to take place at the plasma membrane and in the endocytic pathway, mostly in late endosomes/multivesicular bodies and recycling endosomes. Specifically, lipid rafts and the role of cholesterol in prion propagation have been highlighted, and recent work demonstrated that in cultured neurons and in hippocampi of prion-infected mice cholesterol synthesis and the levels of unesterified cholesterol are upregulated [9-14]. The biosynthesis of brain cholesterol takes place in situ and it does not permeate the blood-brain-barrier (BBB) to reach the peripheral circulation [15]. Therefore, aberrant brain cholesterol metabolism is implicated in the pathologies of various protein misfolding neurodegenerative diseases, including prion diseases [12, 16-21]. Prion infection increases cholesterol production resulting in its accumulation in the brain. Furthermore, cholesterol transporter ATPbinding cassette transporter type A1 (ABCA1)-mediated neuronal cholesterol efflux is negatively affected by prion infection, contributing to intracellular accumulation of cholesterol [9-14, 22-25].

The major pathway of brain cholesterol elimination depends on the brain specific enzyme cholesterol 24-hydroxylase (Cytochrome P450 46A1 (Cyp46A1)). The Cyp46A1 converts cholesterol into 24(S)-hydroxycholesterol (24-OHC), a molecule which can permeate the BBB and reach the peripheral circulation system for further metabolism [21, 25-29]. The brain cholesterol homeostasis and turnover $(45-50 \%)$ is achieved through activation of Cyp46A [30-33]. However, the role of Cyp46A1 in prion diseases has not yet been studied. Therefore, we investigated the expression patterns of Cyp46A1 in brains of mice infected with different prion strains (RML, 22L, and ME7) and in post-mortem brains of SCJD patients. For the first time, we demonstrate that Cyp46A1 protein level is reduced at terminal stages of prion disease in mice independent of the prion strain used for infection, and more importantly, in post-mortem brains of sCJD patients. Hypothesizing that this reduction causes a loss-of-function of Cyp46A1 resulting in increased cholesterol levels upon prion infection, we employed the drug efavirenz (EFV). EFV is a non-nucleoside reverse transcriptase inhibitor that has been used for decades for the chronic treatment of human immunodeficiency virus (HIV) patients. This drug effectively permeates the BBB and has been approved by the food and drug administration (FDA) as an anti-HIV medication since 1998 [34, 35]. Recently, it has been described as an allosteric pharmacological activator of Cyp46A1 [36-41]. Therefore, we argued that EFV treatment will increase the cholesterol export from the brain and reduce prion propagation. We demonstrate here that EFV significantly attenuated $\mathrm{PrP}^{\mathrm{Sc}}$ propagation in prion-infected neuronal cells and primary neuron cultures and does not affect lipid raft integrity or $\operatorname{PrP}^{\mathrm{C}}$ lipid raft association. Oral treatment of mice with EFV starting weeks to months after intracerebral prion inoculation significantly increased the survival times of prion-infected animals.

In summary, we show for the first time a reduction of Cyp46A1 levels in prion disease, and its value as an accessible therapeutic target. The fact that EFV is an FDA-approved medication indicates translational potential of our findings.

\section{Materials and methods \\ Materials}

EFV was purchased from Toronto Research Chemicals Inc., Ontario, Canada. The PK and Pefabloc (protease inhibitor) were purchased from Roche, Germany. All other reagents/chemicals were purchased from SigmaAldrich, USA. The PrP monoclonal antibody (mAb) $4 \mathrm{H} 11$ used in this study to detect PrP has been previously described [42]. The antibodies anti-Cyp46A1 (ab82814, Abcam, USA), anti-flotillin-1 (610,821, Mouse BD Transduction Laboratories) and anti- $\beta$-actin (Cell signaling) were used. Secondary antibody conjugated with peroxidase, goat anti-mouse HRP, was obtained from Jackson Immuno Research, USA.

\section{Ethics statement}

Female FVB mice (6-8 weeks of age; Charles River Lab) and female C57BL/6 J mice (6-8 weeks of age; Jackson Lab) were used in this study. The mice were kept at 12-h (hr)/12-h light/dark cycle and maintained temperature at $23{ }^{\circ} \mathrm{C}$, in an environment with $60 \pm 10 \%$ humidity. The mice were allowed to access food and water ad libitum. All animal experiments described in this study were approved by the University of Calgary Health Sciences Animal Care Committee (approved protocols: AC140165, Bioassay 1; and AC18-0158, Bioassay) according to the guidelines issued by the Canadian Council for Animal Care and ARRIVE guidelines. 


\section{Animal bioassay I}

After acclimatization, FVB mice were randomly divided into four groups of $n=4$ and intracerebrally (i.c.) inoculated with brain homogenate (1\% w/v in PBS; $20 \mu \mathrm{l})$ of non-prion infected mice or terminally sick mice infected with RML, 22-L, and ME-7, respectively. The i.c inoculation procedure was performed using 25-gauge disposable needles under anesthesia. Four mice each were euthanized at 75, 100, 125 DPI and at the terminal stage ( $>150$ DPI) of prion disease. Euthanasia was performed under anesthesia using $5 \%$ isoflurane by $\mathrm{CO}_{2}$ overdose. Terminal stage was reached when progressive clinical signs of advanced prion disease were observed.

\section{Animal bioassay II (EFV treatment)}

After acclimatization, C57BL/6 J mice were randomly assigned into five groups of $n=10$ in each group:

1. RML

2. RML + EFV (0 DPI-DW)

3. RML +EFV (30 DPI-DW)

4. $R M L+E F V(50$ DPI-DW)

5. RML +EFV (30 DPI-IP)

All mice were inoculated under anesthesia i.c. into the right parietal lobe with brain homogenate $(20 \mu \mathrm{l}$ of $0.1 \%)$ from a RML-inoculated terminally sick mouse using a 25 -gauge disposable hypodermic needle. The mice were closely monitored for 10 days for any detrimental effects after i.c. injection. EFV $(0.09 \mathrm{mg} / \mathrm{kg} /$ day $)$ treatment in drinking water was started on the day of inoculation $(0$ DPI-DW) or 30 and $50 \mathrm{dpi}$, according to previously established protocols $[19,41]$. For the other post-treatment group, i.p. injection of EFV (0.05 mg/kg/day) was started at 30 DPI 3 times per week for 130 days. After 130 days EFV was delivered at concentration of $0.09 \mathrm{mg} / \mathrm{kg} /$ day in drinking water. EFV was dissolved in $0.01 \%$ DMSO and added to the drinking water. Every 3 days the EFV solution in drinking water was replaced with fresh EFV solutions and continued until the experimental endpoint. The mice were monitored initially weekly and daily when progressive clinical signs of prion disease were evident. At terminal stage of prion disease, mice were euthanized by $\mathrm{CO}_{2}$ overdose under anesthesia and survival times were recorded. Several mice across all groups were euthanized before they reached terminal prion disease for intercurrent diseases and were excluded from statistical analyses (Additional file 1: Table S1).

\section{Cell lines and EFV treatment}

The murine neuroblastoma cell line N2a was obtained from ATCC (CCL-131). Cell cultures were maintained in
Opti-MEM Glutamax medium (GIBCO, USA) with $10 \%$ fetal bovine serum, and penicillin/streptomycin at $37^{\circ} \mathrm{C}$ in a $5 \% \mathrm{CO}_{2}$ atmosphere. N2a-wt cells are stably transfected cells overexpressing murine PrP. N2a cells persistently infected with mouse-adapted scrapie strains 22L (N2a-22L) or RML (N2a-RML) prions were used in the study [25, 43]. N2a-RML represent a cell line stably overexpressing 3F4-tagged murine PrP [44], in addition to endogenous mouse PrP. CAD5 neuronal cells (a generous gift from Dr. Mahal, Scripps Research Institute, Florida; [45]) were persistently infected with RML or $22 \mathrm{~L}$ prions (CAD5-RML, CAD5-22L) and cultured at $37{ }^{\circ} \mathrm{C}$ in a $5 \%$ $\mathrm{CO}_{2}$ atmosphere in Opti-MEM Glutamax medium containing $10 \%$ bovine growth serum (Hyclone, USA) and penicillin/streptomycin. Cells were treated with EFV at different concentration ( $5 \mu \mathrm{M}, 10 \mu \mathrm{M}, 20 \mu \mathrm{M}$ in DMSO) or with vehicle. After $72 \mathrm{~h}$ of EFV treatment cell lysates were collected and proceeded for analysis.

\section{Cerebellar granular neuron (CGN) culture and EFV treatment}

Newborn (7 days post-natal) C57BL/6 mice (Charles River, Saint Constant, Quebec, Ca) were used for preparing primary cultures of cerebellar granular neurons (CGN). CGN were mechanically extracted from the cerebella of newborn mice and enzymatically dissociated as previously described [46]. Cells were plated at a density of $1.9 \times 10^{3}$ cells $/ \mathrm{mm}^{2}$ on plastic culture wells precoated with $10 \mu \mathrm{g} / \mathrm{ml}$ poly-D-lysine. Cells were cultured in Dulbecco's modified Eagle's medium-Glutamax I high glucose (DMEM) (Life Technologies-Gibco, Ca) supplemented with penicillin and streptomycin (Life Technologies, Ca), 10\% fetal bovine serum (Life Technologies, $\mathrm{Ca}), 20 \mathrm{mM} \mathrm{KCl}$, and $\mathrm{N} 2$ and $\mathrm{B} 27$ neuronal supplements (Life Technologies, Ca). Cells were incubated at $37{ }^{\circ} \mathrm{C}$ in a humidified 5\% CO2 atmosphere. Every week, the medium was supplemented with glucose $(1 \mathrm{mg} / \mathrm{ml})$ and antimitotics, uridine and fluorodeoxyuridine $(10 \mu \mathrm{M})$ (Sigma-Aldrich) to reduce astrocyte proliferation in the culture.

After $48 \mathrm{~h}$ of seeding, CGNs were infected with RML mouse adapted scrapie prions. As previously described [46], RML-infected mouse brain homogenate $(10 \% \mathrm{w} / \mathrm{v}$ in PBS) was sonicated and added at a final concentration of $0.01 \%$ to CGN cultures. After four days, the inoculum was removed, cultures were washed twice with media and fresh media was added for the rest of the experiment.

From 1- or 7-day post infection (dpi) as indicated, until the end of the experiment, infected cultures were treated every 4 days with various concentrations of EFV ( 5 and $10 \mu \mathrm{M}$ ), or with vehicle. Cells were lysed for $\operatorname{PrP}^{\mathrm{Sc}}$ detection at different days post infection as indicated and lysates were processed for further analysis. 


\section{Cell lysis and proteinase $\mathrm{K}$ (PK) digestion}

Cell lysis was done as described previously [46, 47]. For PK digestion, lysates were incubated with $\mathrm{PK}$ at a final concentration of $20 \mu \mathrm{g} / \mathrm{ml}(\mathrm{N} 2 \mathrm{a} / \mathrm{CAD} 5$ cells) and $5 \mu \mathrm{g} / \mathrm{ml}$ (CGN) for $30 \mathrm{~min}$ at $37^{\circ} \mathrm{C}$. PK digestion was terminated by the addition of Pefabloc protease inhibitor. Proteins were precipitated by adding methanol and resuspended in sample buffer for immunoblot analysis.

\section{Immunoblot analysis}

Immunoblot analysis was performed as previously described [46]. Protein samples were re-suspended in TNE buffer (50 mM Tris- $\mathrm{HCl}$ pH 7.5; $150 \mathrm{mM} \mathrm{NaCl}$; 5 mM EDTA) and separated on 12.5\% SDS-PAGE. Electroblotting was done using Amersham Hybond P 0.45 PVDF membranes (Amersham, USA). Membranes were incubated with primary and secondary antibodies as indicated and analyzed using Luminata Western Chemiluminescent HRP Substrates (Millipore, USA). The densitometric analysis of immunoblots was performed using ImageJ.

\section{Preparation of brain homogenates}

Brain homogenates $(\mathrm{BH})$ were prepared in PBS $(10 \%$ $\mathrm{w} / \mathrm{v})$ using a gentle $\mathrm{MACS}^{\mathrm{TM}}$ Dissociator for $2 \mathrm{~min}$ at room temperature, followed by centrifugation at 2,000 $\mathrm{g}$ for $1 \mathrm{~min}$. The homogenates were aliquoted and stored at $-80^{\circ} \mathrm{C}$ until further use. For immunoblotting, $10 \% \mathrm{BH}$ was mixed with equal volume of cold lysis buffer $(10 \mathrm{mM}$ Tris-HCl, pH 7.5, $100 \mathrm{mM} \mathrm{NaCl}, 10 \mathrm{mM}$ EDTA, 0.5\% Triton X-100, 0.5\% sodium deoxycholate) and incubated at $4{ }^{\circ} \mathrm{C}$ overnight. Resulting $5 \% \mathrm{BHs}$ were incubated with either water for no PK or $50 \mu \mathrm{g} / \mathrm{ml}$ of PK (final concentration) for digestion at $37^{\circ} \mathrm{C}$ for $1 \mathrm{~h}$. PK digestion was stopped by addition of proteinase inhibitors (Pefabloc) to both no PK and PK-digested BHs. This was followed by addition of $3 \mathrm{X}$ sample loading buffer and boiling at $95^{\circ} \mathrm{C}$ for 5-7 min. The samples were processed for immunoblotting as described above.

\section{Immunofluorescence staining for Cyp46A1 in mouse brains} Paraffin-embedded mouse brain tissue samples (5 $\mu$ m-thick sections) on gelatin-coated slides were deparaffinized three times with absolute xylene ( $5 \mathrm{~min}$ for each wash) and rehydrated with graded ethyl alcohol (100\% to $70 \%)$. Then they were washed twice with TBST (10 mM Tris-HCl (pH 7.4), $150 \mathrm{mM} \mathrm{NaCl}, 0.05 \%$ Tween 20) for $10 \mathrm{~min}$ and incubated for $1 \mathrm{~h}$ with $2 \%$ normal goat serum as a blocking solution and $0.3 \%$ Triton X-100 in PBS. After blocking, the slides were incubated with primary antibody (rabbit-Cyp46A1 (ab82814) diluted 1:100 in blocking solution overnight at $4{ }^{\circ} \mathrm{C}$. After primary antibody incubation, the sections were washed twice for
5 min each and incubated for $1 \mathrm{hr}$ with Alexa Fluor 488 goat anti-rabbit or Alexa FluorTM 555 goat anti-rabbit secondary antibodies (Jackson Immunoresearch) (1:100). Coverslips were mounted with Dako fluorescent mounting medium (Molecular Probe, Eugene, OR). The immunofluorescence images were captured at same conditions for all images using a confocal laser scanning microscope (Zeiss LSM 700 confocal microscope). Five images per section (tissue) were captured from each respective group. Confocal images were converted to tagged image file format (TIF). The quantification of the immunofluorescence intensity in the same region of the brain areas (cerebellum, medulla) in the TIF images for all groups was performed using ImageJ software. The background of TIF images was optimized according to the threshold intensity, and the immunofluorescence intensity was analyzed at specified threshold intensity for all groups at same conditions and was expressed as the relative integrated density between the groups.

\section{Immunofluorescence staining in neuronal cells}

The non-infected CAD5 and infected CAD5-RML and CAD5-22L and N2a-RML cells were seeded on coverslips in 12 or 24 well plates. N2a-RML cells were treated with EFV $(20 \mu \mathrm{M})$ for 3 days for $\operatorname{PrP}^{\mathrm{Sc}}$ staining. Control cells were treated with DMSO for 3 days. After reaching $70 \%$ confluence the cells were fixed with $4 \%$ paraformaldehyde in PBS for $20 \mathrm{~min}$ at room temperature (RT) and washed three times with PBS. Cells were incubated for $1 \mathrm{~h}$ with $10 \%$ fetal bovine serum (FBS) as a blocking solution and $0.1 \%$ Triton $\mathrm{X}-100$ in PBS. For $\mathrm{PrP}^{\mathrm{Sc}}$ staining, cells were treated for $7 \mathrm{~min}$ with $6 \mathrm{M}$ guanidine hydrochloride, washed 3 times with PBS and further incubated with primary antibody $4 \mathrm{H} 11$ or Cyp46A1 diluted 1:100 in blocking solution for $1 \mathrm{~h}$ at RT. After primary antibody incubation, cells were washed three times $(5 \mathrm{~min}$ each) in PBS and further incubated with secondary antibody (Alexa FluorTM 555 goat anti-mouse secondary antibody, Invitrogen -1:500) for $1 \mathrm{~h}$ at RT. Nuclei were stained with DAPI for $10 \mathrm{~min}$. Cells were washed with PBS and after final washes, coverslips were mounted on slides using Mounting Medium (PermaFluor ${ }^{\mathrm{TM}}$, Thermo fisher). Images were collected and processed using a confocal laser scanning microscope (Zeiss LSM 700 confocal microscope) and all the images were taken using the same conditions. Image analysis and quantification of the mean $\mathrm{PrP}^{\mathrm{Sc}}$ intensity per nucleus was done using the Zen Desk 3.2 imaging software with the zone of influence (ZOI) method. For Cyp46A1 the number of original confocal images per well of the chamber slide was five per group and the images were converted into TIF images. The fluorescence intensity of the same region of TIF images for all groups was measured using ImageJ software (National 
Institutes of Health, Bethesda, MD). The TIF image background was optimized according to the threshold intensity and the immunofluorescence intensity at the same threshold intensity for all groups was analysed and was expressed as the relative integrated density of the samples relative to control cells.

\section{Flotation assays for lipid raft isolation}

Lipid rafts were isolated as described previously [11]. Briefly, $3 \times 10^{7} \mathrm{~N} 2 \mathrm{a}-\mathrm{WT}$ cells treated for 3 days with EFV $(20 \mu \mathrm{M})$ or not were solubilized in $400 \mu \mathrm{l}$ cold lysis buffer $(\mathrm{NaCl} 150 \mathrm{mM}$, Tris-HCl pH $7.525 \mathrm{mM}$, EDTA $5 \mathrm{mM}$, and Triton-X $1001 \%$ ) and incubated on ice in the cold room for $30 \mathrm{~min}$. The cell lysates were mixed with Nycodenz 70\% in TNE $(\mathrm{NaCl} 150 \mathrm{mM}$, Tris- $\mathrm{HCl}$ $\mathrm{pH} 7.525 \mathrm{mM}$, EDTA $5 \mathrm{mM}$ ) to a final concentration of $35 \%$ Nycodenz and were overlaid by $200-\mu l$ fractions of Nycodenz solutions with concentrations of 25, 22.5, 20, $18,15,12$, and $8 \%$. After ultracentrifugation $(200,000 \mathrm{~g}$, $4 \mathrm{~h}, 4{ }^{\circ} \mathrm{C}$, Beckmann TLS55 rotor), fractions were collected from the top to the bottom of the gradient and precipitated with methanol for immunoblot analysis.

\section{Data and statistical analyses}

Statistical analyses and histograms were produced using GraphPad Prism software (GraphPad 8, Software, USA). For statistical analysis of immunoblot signals two-tailed independent Student's t-test for two groups or for multiple groups, one-way analysis of variance (ANOVA) followed by Turkey's post hoc test or Dunnett's multiple comparison test, as applicable, was used. Values are expressed as mean \pm SEM. The graphical representation of survival times of animals was done using a KaplanMeier plot. The log rank test was used for statistical analysis of differences between groups in the survival plot with median and pairwise comparisons between control and treated group. Mice euthanized for reasons not related to prion disease were excluded from the analysis. Significance $={ }^{*} p \leq 0.05,{ }^{* *} p \leq 0.01$, and ${ }^{* * * *} p \leq 0.001$.

\section{Results}

Reduced Cyp46A1 level at terminal stages of prion disease in prion-infected mice and SCJD patients

To assess a potential role of Cyp46A1 in prion disease, we analyzed its protein levels at the terminal stage of prion disease after intracerebral (i.c.) inoculation of three well established scrapie strains (RML, 22L and ME7) into FVB mice. The mice were closely monitored for progression of clinical signs of prion disease and animals were euthanized at terminal stage, along with non-infected mock groups of mice. We confirmed prion infection by immunoblot analysis of $\mathrm{PrP}^{\mathrm{Sc}}$ levels upon proteinase $\mathrm{K}$ (PK) digestion of brain homogenates. Results indicated strong signals for $\mathrm{PrP}^{\mathrm{Sc}}$ in all RML-, 22L- and ME7infected FVB mice, while in non-infected (mock) animals we did not detect any $\operatorname{PrP}^{\mathrm{Sc}}$ signal (Fig. 1a, b). Following this confirmation, we assessed the Cyp46A1 levels in the same brain homogenates of RML, 22L and ME7-infected and non-infected mice, respectively, by immunoblot. Cyp46A1 signals were quantified, and the results indicate a significant reduction of Cyp46A1 in brain homogenates at the terminal stage of prion disease (RML, 22L, and ME7; $p<0.01)$ compared to the age-matched noninfected mice (Fig. 1c; $p<0.01$ ). We also found reduced Cyp46A1 immunofluorescence reactivity in the brains of infected mice as compared to the non-infected group (Fig. 1d; $p<0.05$ ).

These results led us to investigate the levels of Cyp46A1 at pre-symptomatic and early clinical stages of prion disease. Therefore, separate cohorts of mice were euthanized at specified periods of time after i.c. infection with RML, 22L and ME7 prions, such as 125 days post infection (DPI), 100 DPI and 75 DPI, along with corresponding non-infected (mock) mice. While at 75 and 100 DPI the mice were at a pre-clinical stage of disease, at 125 DPI early prion signs manifested, such as a slight to moderate rigid tail, and a slightly hunched posture. At all-time points, $\mathrm{PK}$-resistant $\operatorname{PrP}^{\mathrm{Sc}}$ was detectable in brain homogenates of all infected mice (Additional file 1: Fig. S1ab, S2a, b \& S3a, b). However, no significant differences in Cyp46A1 expression levels were measurable by immunoblot (Additional file 1: Fig. S1c, S2c \& S3c).

To confirm results in the most common human prion disease and in order to determine the translational significance of Cyp46A1 reduction in prion-infected mice, post-mortem brain homogenates of four different healthy individuals (NBH: normal brain homogenates) and four different sporadic CJD patients (sCJD) (Fig. 2a) were analyzed by immunoblot for Cyp46A1 levels. Of note, as in the experimental models of prion disease, a significant reduction of Cyp46A1 levels in the brains of sCJD patients as compared to the healthy individuals was observed, confirming the relevance of our finding to human prion diseases $(p<0.05)$.

\section{Cyp46A1 is reduced in neuronal cells persistently infected with prions}

Next, in vitro experiments were performed to confirm that the reduced level of Cyp46A1 in animal models and human SCJD patients was associated with prion infection. We used the mouse catecholaminergic neuronal cell line CAD5 persistently infected with RML and 22L prions (CAD5-RML; CAD5-22L). Prion infection was confirmed by immunofluorescence assay using conditions for the specific detection of $\mathrm{PrP}^{\mathrm{Sc}}$ (Fig. 3a). Next, we performed confocal microscopy for assessing Cyp46A1 


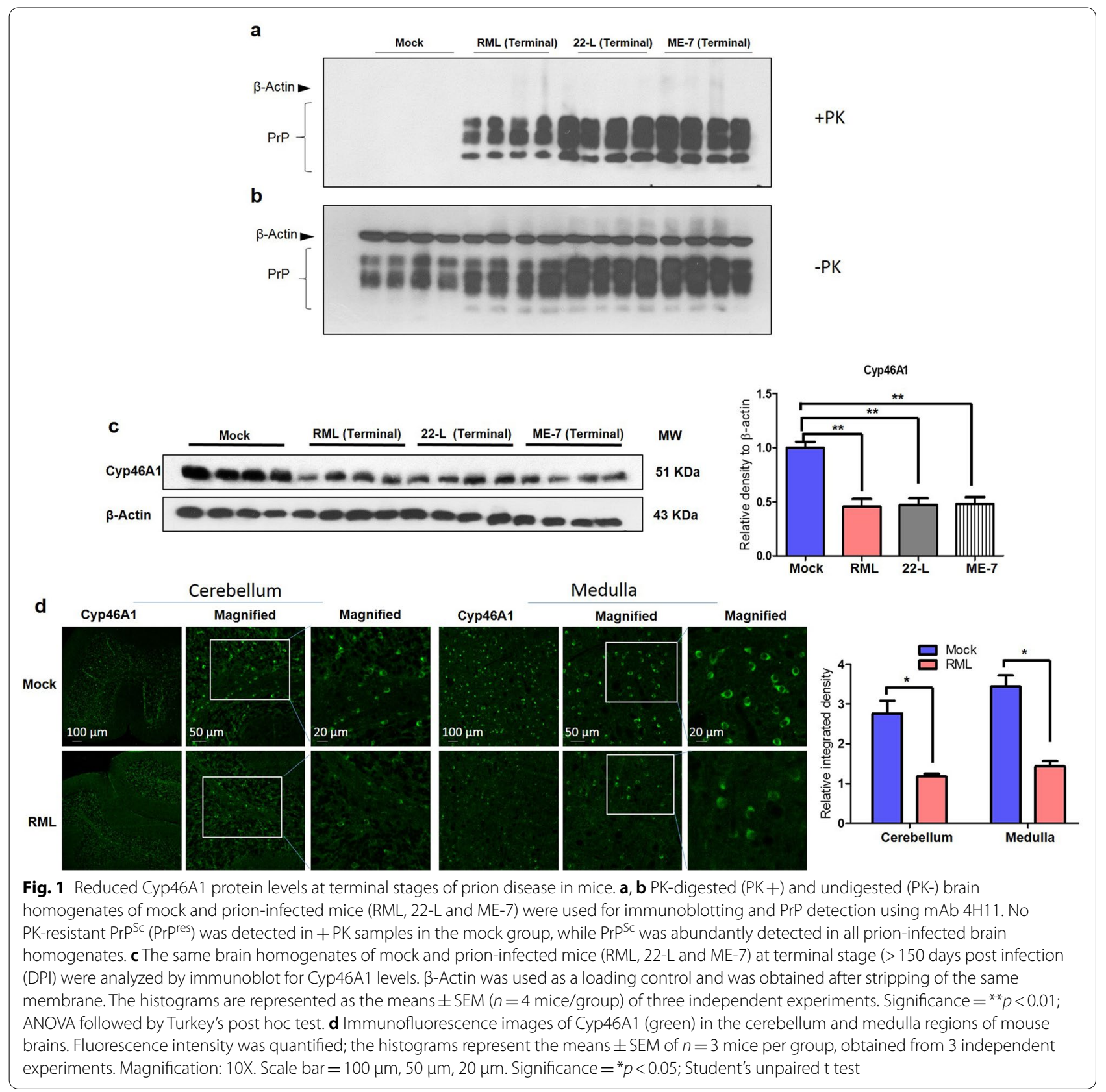

immunofluorescence reactivity. The confocal microscopy results indicated significantly reduced Cyp46A1 immunofluorescence reactivity in the RML- or 22L-infected CAD5 neuronal cells (CAD5-RML; CAD5-22L) as compared to the uninfected CAD5 neuronal cells (Fig. 3b, c; $p<0.01 ; p<0.01)$. These results were verified by immunoblot. Of note, we found significantly reduced Cyp46A1 levels in CAD5-RML and CAD5-22L cells as compared to the uninfected CAD5 neuronal cells (Fig. 3d, e; $p<0.01$; $p<0.05)$.
The reduction of Cyp46A1 we observed both in vivo and in vitro indicates that Cyp46A1 has a role in prion diseases. Overall, our results suggest that increasing Cyp46A1 activity in prion diseases can be a novel therapeutic approach in prion diseases.

\section{EFV treatment reduced $\mathrm{PrP}^{\mathrm{Sc}}$ in prion infected neuronal cells}

Next, we aimed to use the antiretroviral drug and allosteric Cyp46A1 activator EFV as a potential therapeutic. EFV via activation of Cyp46A1 has a significant beneficial 


\begin{tabular}{|c|c|c|c|c|c|c|c|c|}
\hline a & & & & & \multirow[b]{2}{*}{ b } & \multirow[b]{2}{*}{$\mathrm{NBH}$} & \multirow[b]{2}{*}{ sCJD patients } & \multirow{3}{*}{$\begin{array}{c}\text { MW } \\
51 \mathrm{KDa}\end{array}$} \\
\hline $\begin{array}{l}\text { Case } \\
\text { number }\end{array}$ & Age & Gender & $\begin{array}{l}\text { CJD } \\
\text { diagnosis }\end{array}$ & $\begin{array}{l}\text { Disease } \\
\text { duration }\end{array}$ & & & & \\
\hline & & & & (months) & Cyp46A1 & 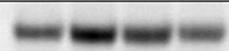 & 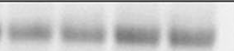 & \\
\hline 1 & 72 & $\mathrm{~F}$ & - & N/A & & & & \\
\hline 2 & 60 & $M$ & - & N/A & $\beta$-Actin & extecteges & 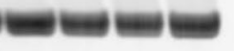 & $43 \mathrm{KDa}$ \\
\hline 3 & 78 & $M$ & - & N/A & & * & * & \\
\hline 4 & 61 & M & - & N/A & & 5 & & \\
\hline 5 & 69 & $M$ & sCJD & 2.5 & & 年 & & \\
\hline 6 & 63 & $\mathrm{~F}$ & SCJD & - & & & 1 & \\
\hline 7 & 60 & $\mathrm{~F}$ & SCJD & 1 & & 吾 $0.5-$ & & \\
\hline 8 & 53 & $M$ & SCID & 1 & & & & \\
\hline & & & & & & NBH & sCJD patients & \\
\hline $\begin{array}{l}\text { Fig. } 2 \text { Redu } \\
\text { normal brain } \\
(\mathrm{NBH}) \text { and } \mathrm{s} C \\
\text { the means } \pm\end{array}$ & $\begin{array}{l}\text { Cyp46A1 I } \\
\text { nogenates } \\
\text { datients. } \beta \\
\text { ( } n=4 \text { hu }\end{array}$ & $\begin{array}{l}\text { in human s } \\
\text { four differe } \\
\text { was used } \\
\text { (group) of }\end{array}$ & $\begin{array}{l}\text { brains. a Dem } \\
\text { poradic CJD p } \\
\text { oading contro } \\
\text { e independen }\end{array}$ & $\begin{array}{l}\text { raphic detail } \\
\text { ents (sCJD). } \\
\text { nd was obta } \\
\text { xperiments. }\end{array}$ & $\begin{array}{l}\text { e post-morten } \\
6 \mathrm{~A} 1 \text { levels in } \mathrm{t} \\
\text { ter stripping o } \\
\text { ance }={ }^{*} p<0 \text {. }\end{array}$ & $\begin{array}{l}\text { brain of four differe } \\
\text { he brain homogenat } \\
\text { f the same membrar } \\
\text { 05; Student's unpaire }\end{array}$ & $\begin{array}{l}\text { nt healthy individual } \\
\text { es of healthy individu } \\
\text { ne. The histogram rep } \\
\text { d t test }\end{array}$ & $\begin{array}{l}\text { (NBH: } \\
\text { als } \\
\text { resents }\end{array}$ \\
\hline
\end{tabular}

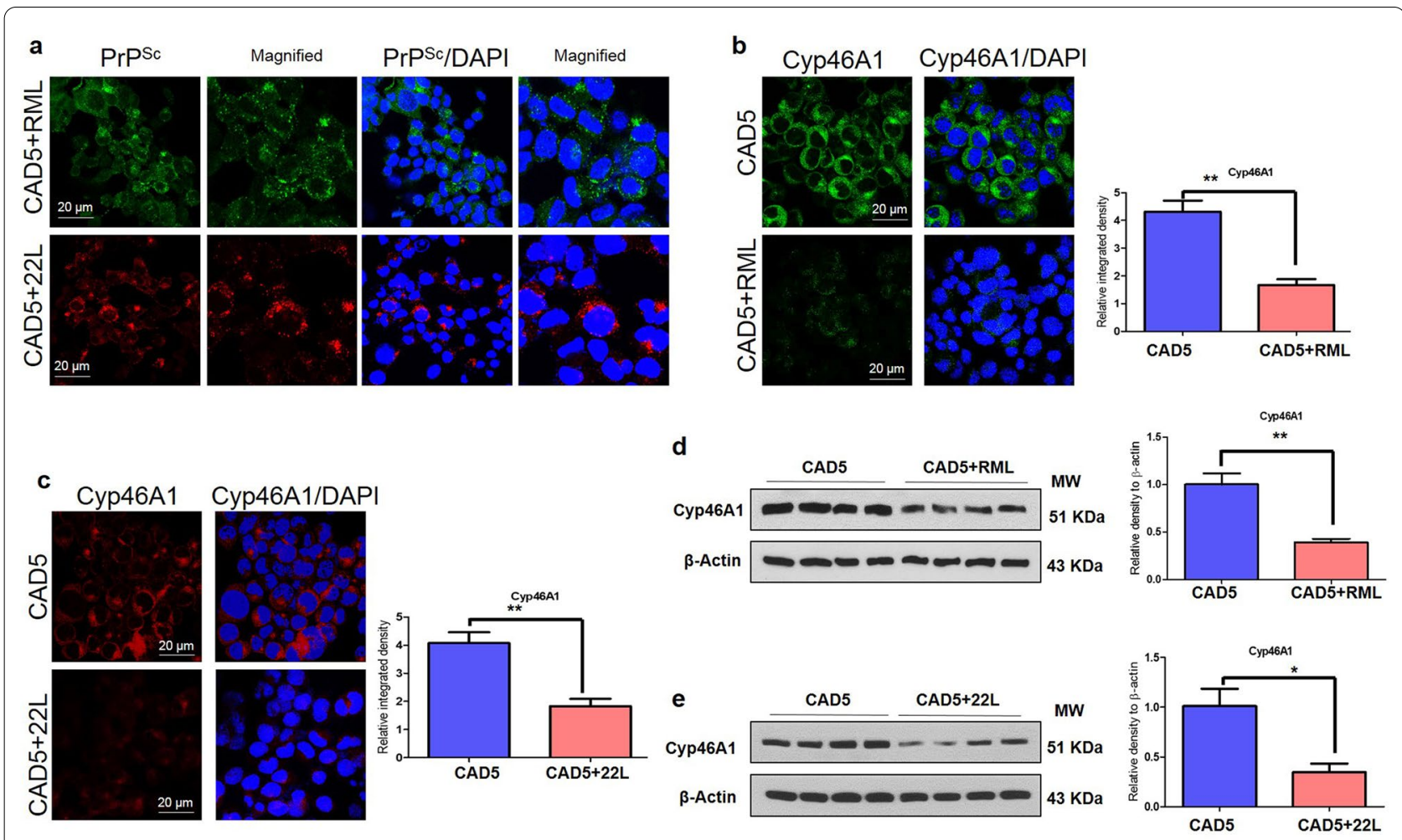

Fig. 3 Cyp46A1 levels in prion-infected neuronal cells. a Immunofluorescence images of PrPSc (Green: Alexa Fluor 488; Red: Alexa Fluor ${ }^{\text {TM }} 555$; Blue: DAPI) for CAD5-RML and CAD5-22L. Magnification: 63X. Scale bar= $20 \mu \mathrm{m}$. b, c Immunofluorescence analysis of Cyp46A1 (Green: Alexa Fluor 488; Blue: DAPI) for CAD5 and CAD5-RML (Red: Alexa Fluor ${ }^{\mathrm{TM}}$ 555; Blue: DAPI) and for CAD5 and CAD5-22L cells. Fluorescence intensity was quantified; data are indicated as the mean \pm SEM for $n=5$ images per group from 3 independent experiments. Magnification: $63 X$. Scale bar $=20 \mu \mathrm{m}$. Significance $={ }^{*} p<0.05$; Student's unpaired t test. $\mathbf{d}$, e Immunoblot results of Cyp46A1 in CAD5, CAD5-RML and CAD5-22L cells. $\beta$-Actin was used as a loading control and was obtained after stripping the same membrane. The histograms depict the means \pm SEM of three independent experiments. Significance $={ }^{* *} p<0.01$; Student's unpaired t test 
effect on the regulation of impaired brain cholesterol metabolism [36-41]. We used different neuronal cell lines (N2a and CAD5) infected with RML or 22L prions to assess a potential inhibitory effect of EFV treatment on prion propagation. To this end, N2a-RML, CAD5-RML and CAD5-22L cells were treated with EFV at different nontoxic concentrations $(5 \mu \mathrm{M}, 10 \mu \mathrm{M}, 20 \mu \mathrm{M})$ for 3 days. Cells treated with EFV solvent served as a control. The cell lysates were subjected to proteinase $\mathrm{K}(+\mathrm{PK})$ digestion or not and used for the analysis of PrP signals by immunoblot. The immunoblot results and quantification of the PK-digested samples indicated that EFV treatment significantly reduced the $\mathrm{PrP}^{\mathrm{Sc}}$ level in N2a-RML, CAD5RML and CAD5-22L cells in a concentration dependent manner as compared to the non-treated control cells. Analysis of cell lysates without PK digestion using anti$\mathrm{PrP}$ antibody $4 \mathrm{H} 11$ reflected the decrease of $\mathrm{PrP}^{\mathrm{Sc}}$ levels by a reduction of total $\operatorname{PrP}$ (Fig. $4 \mathrm{a}-\mathrm{f} ; p<0.01 ;<0.05$ ). Further, we confirmed these findings by confocal microscopy upon $\operatorname{PrP}^{\mathrm{Sc}}$-specific staining of prion-infected cells. The results revealed that EFV treatment significantly reduced the immunofluorescence reactivity of $\mathrm{PrP}^{\mathrm{Sc}}$ in

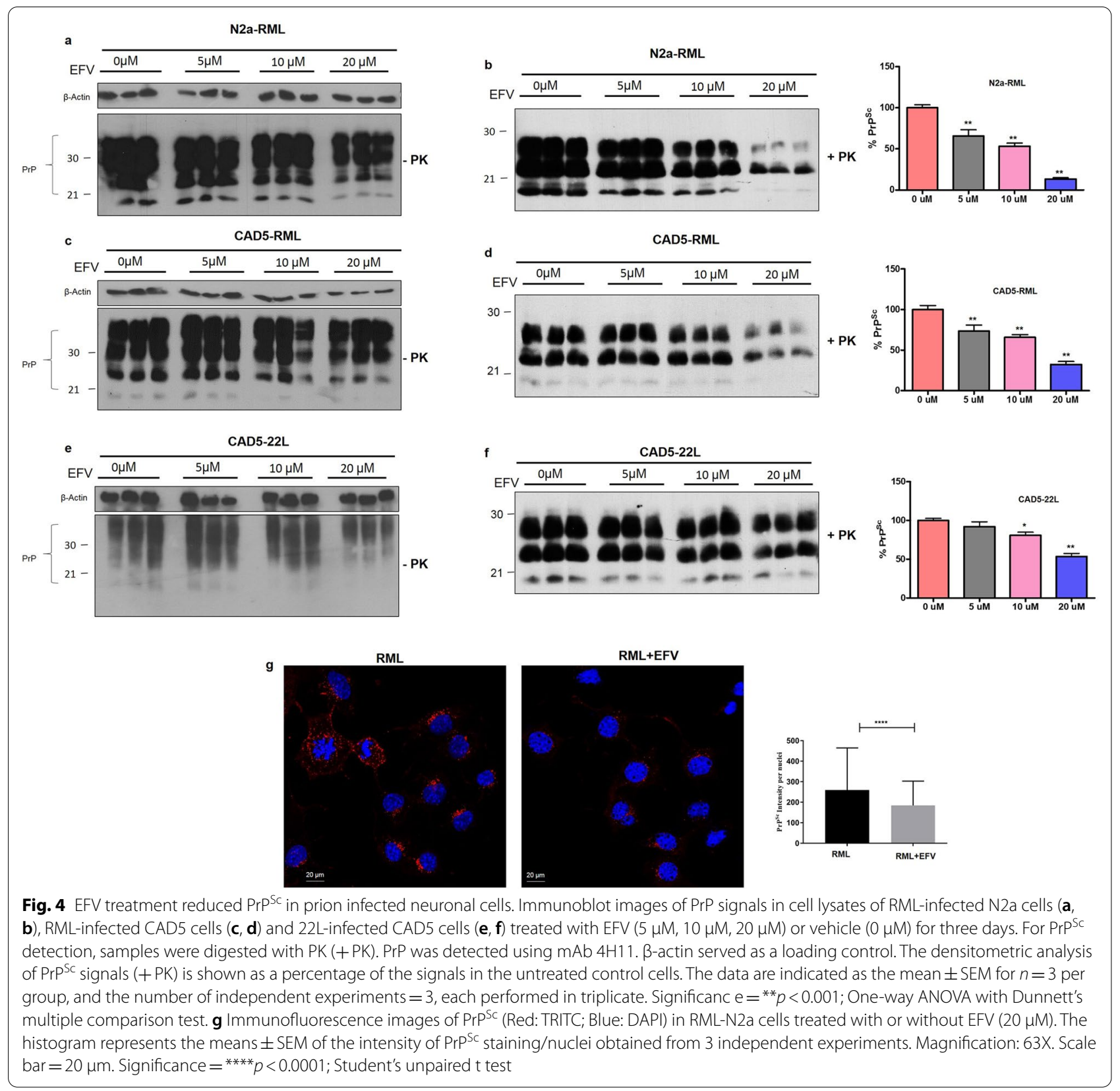


RML-N2a cells compared to non-treated control cells (Fig. 4g; $p<0.0001$ ).

Next, we tested the efficacy of EFV treatment to reduce $\mathrm{PrP}^{\mathrm{Sc}}$ propagation in a more physiological model, namely prion-infected primary cerebellar granular neuronal (CGN) cultures. CGNs prepared from newborn $\mathrm{C} 57 \mathrm{Bl} / 6$ mice were infected with $22 \mathrm{~L}$ prions. EFV $(5 \mu \mathrm{M}$, $10 \mu \mathrm{M})$ was added twice a week, starting at day 1 (D1) and day 7 (D7), respectively, after infection. Cells were lysed at different time points after infection. Of note, in the prion-infected primary CGN culture, EFV treatment also reduced the $\operatorname{PrP}^{\mathrm{Sc}}$ levels as observed by immunoblot analysis of PK digested cell lysates. This effect was particularly evident on day 21 post infection when EFV treatment was started at 1 day post infection at a concentration of $10 \mu \mathrm{M}$ (Additional file 1: Fig. S4). Overall, these results show that EFV treatment has a strong anti-prion effect in neuronal cell lines and primary neuronal cells which is neither dependent on prion strain nor cell line specific, proposing EFV as a potent therapeutic in prion diseases.

\section{EFV treatment does not affect $\operatorname{PrP}^{\mathrm{C}}$ level and lipid raft integrity in neuronal cells}

Manipulation of cellular cholesterol turnover can affect lipid raft integrity and $\operatorname{PrP}^{\mathrm{C}}$ trafficking or amount. Therefore, we used non-infected CAD5 neuronal cells to determine effects of EFV treatment on $\mathrm{PrP}^{\mathrm{C}}$. The CAD5 neuronal cells were treated with the same concentrations $(5 \mu \mathrm{M}, 10 \mu \mathrm{M}, 20 \mu \mathrm{M})$ of EFV or with vehicle for 3 days as used in the prion-infected cells. The immunoblot results of cell lysates showed that there was no significant difference in total $\mathrm{PrP}^{\mathrm{C}}$ levels in the EFV-treated groups at all concentrations as compared to the control group (Fig. 5a).

Primarily, $\operatorname{PrP}^{\mathrm{C}}$ is localized at the plasma membrane and particularly in lipid rafts, which is important for the physiological functions of $\operatorname{PrP}^{C}$ [9-14]. Therefore, we used CAD5 cells treated with or without EFV to analyze the association of $\operatorname{PrP}^{\mathrm{C}}$ with lipid rafts. A density gradient procedure was applied according to previous protocol $[11,12]$ for separation of lipid raft domains. Fractions of the gradient were analyzed by immunoblot for $\mathrm{PrP}^{\mathrm{C}}$ and flotillin, a marker for lipid rafts. This revealed that highest levels of $\mathrm{PrP}^{\mathrm{C}}$ existed in fractions 3-6, coherent with the signals of flotillin in fractions 3-6. In EFV treated cells, $\mathrm{PrP}^{\mathrm{C}}$ and flotillin co-fractionated and were mainly found in the same fractions as in non-treated cells (Fig. 5b, c).

These results indicated that EFV treatment has no adverse effect on the total $\operatorname{PrP}^{\mathrm{C}}$ level. Lipid raft integrity was maintained upon EFV treatment and lipid raft association of $\operatorname{PrP}^{\mathrm{C}}$ was not affected.
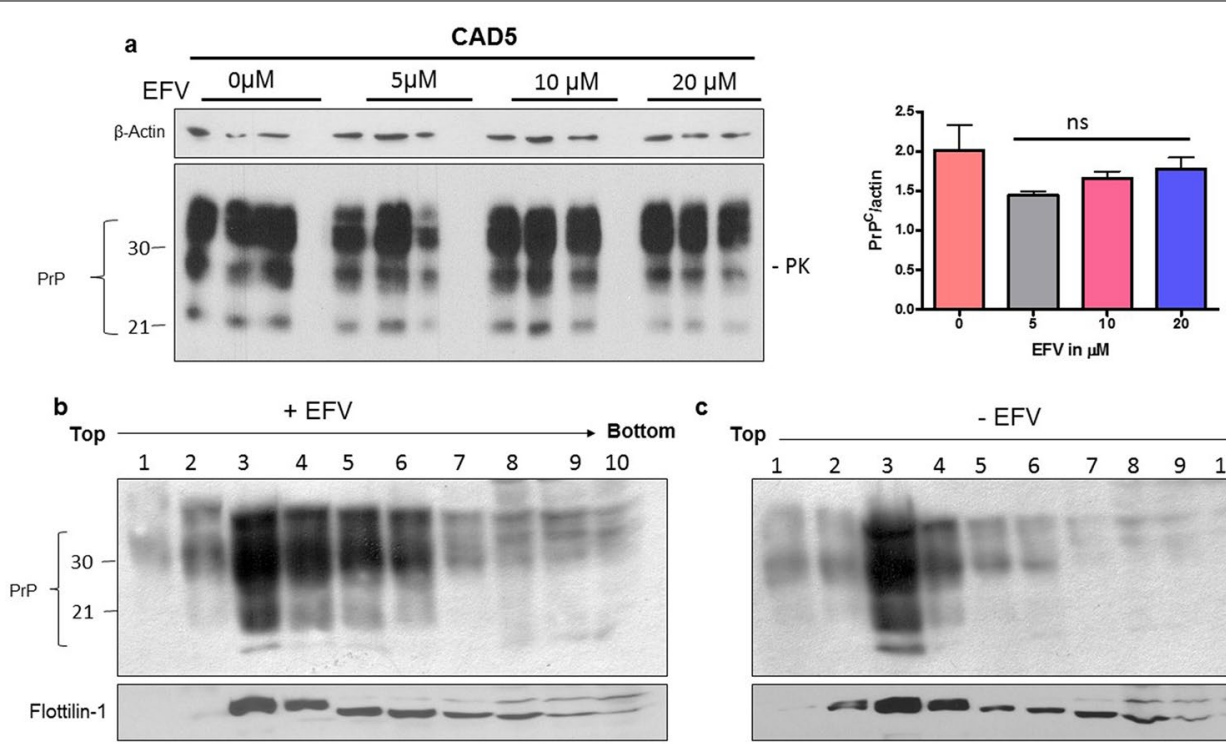

c Top

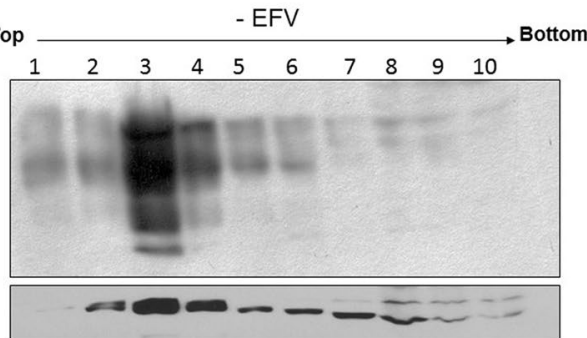

Fig. 5 The effect of EFV treatment on PrPC level and lipid raft association in neuronal cells. a Non-infected CAD5 cell were treated with EFV (5 $\mu \mathrm{M}$, $10 \mu \mathrm{M}, 20 \mu \mathrm{M}$ ) or vehicle and $\mathrm{PrPC}^{C}$ in cell lysates was detected by immunoblot using mAb 4H11. $\beta$-Actin was used as a loading control. The data are indicated as the mean \pm SEM for $n=3$ per group, and the number of independent experiments $=3$, each performed in triplicate. Significance $=$ no significant (ns) differences $\mathbf{b}, \mathbf{c}$ N2a-WT cells treated with EFV (+EFV) or not (-EFV) were lysed in cold Triton-X 100 and subjected to flotation density gradients. Fractions 1-10 were collected from the top to the bottom of the gradient and analyzed by immunoblot using anti-PrP antibody $4 \mathrm{H} 11$ and anti-flotillin-1 as a lipid raft marker. b Representative immunoblot result of $\operatorname{PrP}$ in the fractions of cells treated with EFV. c Representative immunoblot result of PrP in the fractions of cells without EFV treatment 
Oral EFV treatment delays prion disease and extends survival times of prion-infected animals

The significant inhibitory effects on $\mathrm{PrP}^{\mathrm{Sc}}$ propagation of the Cyp46A1 activator EFV in in vitro models of prion infection, and the reduced expression of Cyp46A1 in prion-infected mice, sCJD patients and prion-infected neuronal cells, inspired us to evaluate EFV effects in an animal model of prion disease. The EFV treatment was selected at the lowest dose $(0.09 \mathrm{mg} / \mathrm{kg} /$ day $)$ previously published to activate Cyp46A1 in mouse brains, and is 300-400-fold lower than that used for chronic treatment of HIV patients $[19,41]$. In one treatment paradigm, we started the low dose $(0.09 \mathrm{mg} / \mathrm{kg} /$ day $)$ EFV treatment applied orally in drinking water on the same day (0 DPI), at 30 DPI or at 50 DPI of intracerebral infection of $\mathrm{C} 57 \mathrm{Bl} / 6$ mice with RML prions. Treatment was continued until the experimental endpoint at which mice reached the terminal stage of prion disease $[19,41]$. The survival times of the EFV-treated mice (RML+EFV (0 DPI-DW) were increased when compared with untreated, RML-infected control mice [RML,
$170.9 \pm 3.430 ;$ RML + EFV (0 DPI-DW), $182.3 \pm 3.496]$ and the mean of the extended survival time of treated mice was $11.40 \pm 4.968$ days compared with RMLinfected mice (Fig. 6a).

Interestingly, when we started EFV treatment at 30 or $50 \mathrm{DPI}$, the survival time of the mice was even more extended. The survival times in both treatment groups were significantly increased compared with untreated, RML-infected control mice [Fig. 6b; RML 170.9 \pm 3.430 ; RML + EFV (30 DPI-DW), 189.6 \pm 2.489$)$ ]; [Fig. 6c; RML $170.9 \pm 3.430$; RML + EFV (50 DPI-DW), 187.0 \pm 3.698 ]. The mean extended survival time of mice revealed a significant prolongation of $18.67 \pm 4.238$ [Fig. 6b; RML+EFV (30 DPI-DW)] and 16.11 \pm 5.039 [Fig. 6c; RML + EFV (50 DPI-DW)] days, respectively, compared to the non-treated and infected control group.

In order to achieve more control on the drug dosage received by each mouse, we included another treatment paradigm for one group of mice. We administered EFV intraperitoneally (I.P) starting on day 30 post infection at a concentration of $0.05 \mathrm{mg} / \mathrm{kg}$ three times a week until a

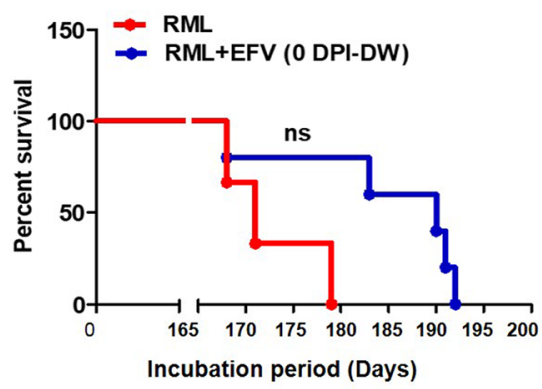

C

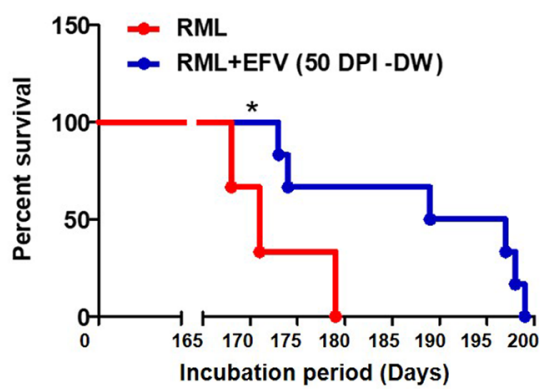

b

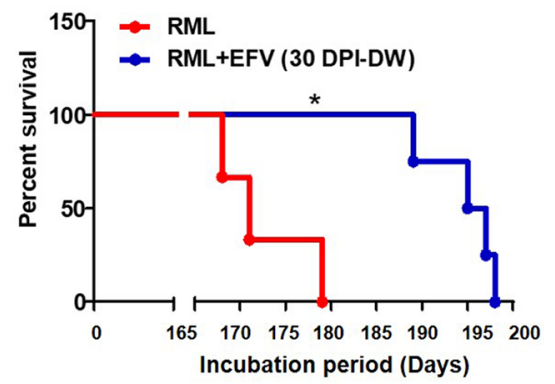

d

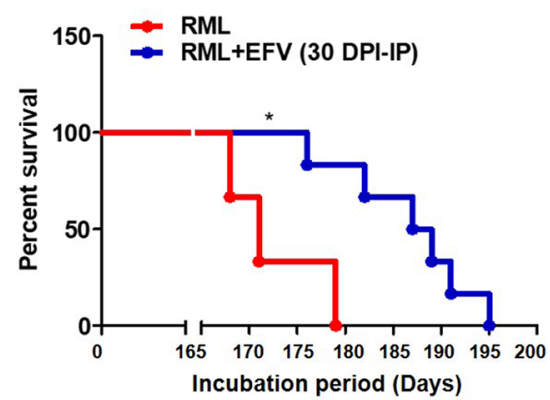

Fig. 6 Oral EFV treatment delays prion disease and extends survival of prion-infected animals. a The representative Kaplan-Meier plot indicates the percent survival of RML-infected mice in the untreated group ( $n=9$ mice) and EFV-treated group RML +EFV ( 0 DPI-DW) ( $n=7$ mice), using log rank test for statistical analysis. $\mathbf{b}$ The representative Kaplan-Meier plot indicates the percent survival of RML-infected mice in the untreated group ( $n=9$ mice) and EFV-treated group RML + EFV (30 DPI-DW) ( $n=9$ mice), using log rank test for statistical analysis. c The representative KaplanMeier plot indicates the percent survival of RML-infected mice in the untreated group ( $n=9$ mice) and EFV-treated group RML + EFV (50 DPI-DW) ( $n=8$ mice), using log rank test for statistical analysis. $\mathbf{d}$ The representative Kaplan-Meier plot indicates the percent survival of RML-infected mice in the untreated group ( $n=9$ mice) and EFV-treated group RML + EFV (30 DPI-IP) ( $n=7$ mice), using log rank test for statistical analysis. NS $p>0.05$, ${ }^{*} p<0.05$. The $x$-axes depict the days post i.c. infection with RML prions 
130 DPI. Due concerns of stress induced by continuous I.P injections, after 130 DPI we continued with EFV treatment $(0.09 \mathrm{mg} / \mathrm{kg} /$ day $)$ supplied in drinking water until the end of the experiment. Notably, in this treatment group the survival times were also significantly increased compared with untreated, RML-infected control mice [Fig. 6d; RML, 170.9 \pm 3.430 ; RML +EFV (30 DPI-IP, $185.8 \pm 2.111)]$. The mean extended survival times of mice were significantly prolonged by $14.86 \pm 4.154$ days as compared to RML-infected and untreated mice (Fig. 6d). These results unveiled that as the prion disease progressed towards the terminal stage, EFV treatment induced a significant prolongation of survival of prioninfected animals.

\section{Discussion}

The failure and disappointing outcomes of clinical trial to treat human prion diseases and the potential risk of zoonosis urges research to identify novel therapeutic targets to treat these deadly diseases. To the best of our knowledge, our study provides the first evidence of significantly decreased levels of Cyp46A1 in prion-infected neuronal cells, in brains of mice infected with different prion strains at the terminal disease stage and most importantly, in post-mortem brains of sCJD patients. In brains of mice or humans with terminal prion disease Cyp46A1 might be reduced because of the loss of neurons; however, our findings of lower Cyp46A1 levels in prion-infected neuronal cells that do not exhibit signs of cell death as compared to non-infected cells indicate an association with prion infection. Our finding of Cyp46A1 downregulation is one among other examples showing a specific protein that is affected in prion disease $[48,49]$.

Cholesterol is synthesized locally in the brain, thereby cholesterol homeostasis and metabolism depend on local cholesterol elimination. Notably, the BBB does not allow cholesterol to cross from the brain to the peripheral circulation. The cholesterol elimination rate depends on Cyp46A1, a brain specific enzyme which converts cholesterol into 24-OHC, a molecule which can easily permeate the $\mathrm{BBB}$, and reach the peripheral circulation system for further metabolism $[21,50]$. Cyp46A1 is a member of the cytochrome 450 enzymes family and distributed through different regions of the brain such as hippocampus, cortex, striatum, thalamus and cerebellum [51]. It is primarily expressed in neuronal cells and is considered the main enzyme with a primary role in neuronal cholesterol metabolism $[52,53]$. Reduced levels of CYP46A1 have been associated with other protein misfolding diseases such as Alzheimer's disease (AD), Parkinson's disease (PD) and Huntington's disease (HD) as well as other neurodegenerative diseases e.g. Niemann-Pick disease type $\mathrm{C}$ (NPC) [17-21]. On the other hand, the overexpression and pharmacological activation of Cyp46A1 induce beneficial effects and rescue brain disorders [36-41]. The Cyp46A1 metabolite 24-OHC is a local, non-toxic and neuroprotective metabolite acting as an activator of liver $\mathrm{X}$ receptors, which have a key role in the functionality of ABCA1 and other cholesterol efflux genes (apolipoproteins) in both neuronal and glial cells which subsequently regulate brain cholesterol homeostasis and turnover. The 24-OHC is responsible for regulating the activity of various transcription factors and mediators e.g. sterol regulatory element-binding protein 2 , involved in cholesterol homeostasis in the brain [31-34]. Further, Cyp46A1 is contributing to protein phosphorylation and ubiquitination as well as to many cellular signaling pathways and events such as endo-lysosomal trafficking, autophagy, synaptic trafficking and neuronal survival signaling such as brain derived neurotropic factor (BDNF) and TrkB receptor signaling $[17-21,53,54]$. Our results, together with evidence from other studies indicate a role of Cyp46A1 in aberrant brain cholesterol metabolism in neurodegenerative diseases and that it would be a valuable and novel drug target in prion diseases.

Interestingly, in vitro and in vivo findings demonstrated that neuronal cholesterol synthesis and amount are increased in prion infection [9-12, 26], suggesting that elevated cholesterol might be a contributing factor in the pathogenesis of prion disease. Our findings of reduced Cyp46A1 levels in prion-infected neuronal cells and in vivo in mouse brains and post-mortem brain homogenates of SCJD patients provide an explanation since the rate of cholesterol export from the brain will be affected by a reduction of Cyp46A1. Upon prion infection, ABCA1 is displaced from lipid rafts and the cell surface and internalized to intracellular compartments leading to a loss of function. ABCA1 is one of the complementary pathways responsible for neuronal cholesterol efflux. Thus, prion infection interferes with neuronal cholesterol efflux through reduction of Cyp46A1 and deregulation of $\mathrm{ABCA} 1$ function. Since ABCA1 is regulated by Cyp46A1 and 24-OHC, its deregulation might be a consequence of Cyp46A1 reduction. Eventually, the impairments of cholesterol efflux pathways upon prion infection lead to an increase and accumulation of cholesterol [24-26]. Such high cholesterol in membranes might favor $\mathrm{PrP}^{\mathrm{Sc}}$ replication. Thereby, the process of $\operatorname{PrP}^{\mathrm{C}}$ conversion into $\operatorname{PrP}^{\mathrm{Sc}}$ resulting in alleviation of cholesterol elimination might continue as a vicious cycle implicated in the progression of prion disease. Therefore, it is required to explore mechanisms through which aberrant neuronal cholesterol metabolism can be regulated to halt the propagation of $\operatorname{PrP}^{\mathrm{C}}$ to $\operatorname{PrP}^{\mathrm{Sc}}$ and subsequently the severity of prion disease. 
In line with this, we demonstrate here that Cyp46A1 activation represents a novel and efficient therapeutic strategy against prion diseases. We used treatment with EFV, an antiretroviral drug known to activate Cyp46A1 and achieved a significant reduction of $\operatorname{PrP}^{\mathrm{Sc}}$ propagation in prion-infected neuronal cells and primary CGN cultures (Fig. 4a-g; Additional file 1: Fig. S4). The exact mechanism by which $\mathrm{PrP}^{\mathrm{C}}$ converts into $\mathrm{PrP}^{\mathrm{Sc}}$ is not comprehensively known. On a subcellular level, a large body of evidence indicates that this conversion occurs in lipid rafts of the plasma membrane. Lipid rafts are membrane microdomains enriched in cholesterol and sphingolipids and harbor many glycosyl phosphatidyl inositol (GPI)-anchored proteins. Both $\operatorname{PrP}^{\mathrm{C}}$ and $\operatorname{PrP}^{\mathrm{Sc}}$ are GPI-anchored proteins and found in lipid rafts. It has been shown that $\operatorname{PrP}^{\mathrm{Sc}}$ propagation can be prevented by reducing cellular cholesterol, e.g. by treatment with statins, cyclodextrin or amphotericin B, thereby destroying the integrity of lipid raft microdomains $[55,56]$. We reported that cholesterol is required for the distribution and localization of $\operatorname{PrP}^{\mathrm{C}}$ at the cell surface, a pre-requisite for propagation of $\operatorname{PrP}^{\mathrm{Sc}}[23,24]$. Treatment with many of these cholesterol-lowering drugs interferes with cellular $\operatorname{PrP}^{\mathrm{C}}$ content and its lipid raft association, raising concerns about compromised function of $\operatorname{PrP}^{\mathrm{C}}$ in signaling pathways. Notably, EFV treatment neither affects $\operatorname{PrP}^{\mathrm{C}}$ levels nor its lipid raft association. Rather than resulting in cholesterol depletion, EFV treatment enhances cholesterol turnover at the plasma membrane [21, 38, 57], suggesting an alternative, novel anti-prion mechanism that does not primarily affect $\operatorname{PrP}^{\mathrm{C}}$.

Oral treatment of prion-infected mice significantly prolonged the survival of animals and delayed the progression of prion disease (Fig. 6a-d). EFV is an allosteric activator of Cyp46A1. It crosses the BBB and has been used for the chronic treatment of HIV patients for decades, at much higher doses as used here. Several lines of evidence showed that oral EFV treatment rescues memory deficits, reduces amyloid beta and extends the survival of animals [19, 37-41]. In addition, EFV treatment, through regulation of impaired cholesterol metabolism, reduced misfolded proteins e.g. p-tau and amyloid beta, two main hallmarks in AD [58]. Very recently, two studies reported that EFV enhanced the lifespan of mice with brain tumor and in NPC disease $[19,41]$. Mitroi et al. further confirmed that EFV activates Cyp46A1 and mobilizes it to the plasma membrane which is responsible for restoring cholesterol efflux and improving learning and memory functions in NPC disease animal models [19]. Recently, it was reported that Cyp46A1 overexpression and its activation by EFV, respectively, mediate sterol flux, significantly contribute to the plasma membrane properties and regulate various kinases such as cyclin-dependent kinase- 5 and glycogen synthase kinase- 3 which have a role in the formation of misfolding proteins e.g. p-tau and amyloid beta [57]. Our results demonstrate that EFV has significant beneficial effects in prion disease, likely associated with Cyp46A1 activation, eventually regulating impaired brain cholesterol metabolism. Our intriguing findings in mouse models of prion disease indicate that EFV treatment in all paradigms of oral application at a very low dosage significantly extended the survival times of prioninfected mice and delayed the progression of prion disease. Notably, this was achieved upon i.c. inoculation of mice, demonstrating that EFV exerted its effects in the brain. As a caveat, our studies were done using mouseadapted scrapie strains and to corroborate the relevance of our findings we suggest further studies using infection models for human prions. Furthermore, the drug was delivered orally in drinking water, which introduces some individual variability with regards to the drug dose received by the mice, depending on their fluid intake. In HIV patients, EFV medication induced some undesirable side effects such as neuropsychiatric adverse effects [59]; however, in all of the previous pre-clinical animal studies and in our bioassay, EFV was applied at lowest doses $(0.09 \mathrm{mg} / \mathrm{kg} /$ day, orally and $0.05 \mathrm{mg} / \mathrm{kg}$, i.p., 3 times/ week) and did not induce any type of side effects. The EFV dosage used here $(0.09 \mathrm{mg} / \mathrm{kg} /$ day $)$ is $300-400$-fold lower than that used for HIV patients, activates Cyp46A1 in mice and has been very effective in all animal models of neurodegenerative diseases $[19,41]$. Other experimental anti-prion drugs have been applied especially the statin drugs which inhibit the cholesterol biosynthesis and they were not effective to prevent the $\operatorname{PrP}^{\mathrm{Sc}}$ accumulation and its associated pathologies $[60,61]$. Hence, the ability of EFV to cross the BBB, the safety profile at low dose, and the efficacy and tolerability of chronic administration through the oral route indicate a strong translational potential.

In summary, our results demonstrate that regulation of brain cholesterol metabolism through pharmacological activation of Cyp46A1 using EFV is a promising approach for intervention in prion diseases.

\section{Supplementary Information}

The online version contains supplementary material available at https://doi. org/10.1186/s40478-021-01162-1.

Additional file 1. Supplementary Information.

\section{Acknowledgements}

This study was funded the Alberta Prion Research Institute and the Canadian Institutes of Health Research. SG is supported by the Canada Research Chairs program, TA receives support through a University of Calgary Eyes High Postdoctoral Recruitment Scholarships, a CIHR Banting fellowship and an Alberta 
Innovates Postdoctoral Scholarship. We are grateful to Dr. Lilian Oribhabor and Bukola Alli for excellent animal care.

\section{Authors' contributions}

T.A., and S. G., designed the research, wrote the manuscript and rearranged the data. T. A., S. G., S.H., S. N., W. T., and I. Z. performed experiments related to immunoblots. T.A., S. H., W. T., and I.Z. conducted bioassays. T.A., P.C. and S. Y. S. performed confocal microscopy. V.S. and H.M.S critically edited and reviewed the manuscript. All authors reviewed, edited, and approved the manuscript. S.G. is the corresponding author and holds all the responsibilities related to this manuscript. All authors read and approved the final manuscript.

\section{Availability of data and materials}

All data required to validate our hypotheses in the paper are provided in the paper and/or the Supplementary Materials. Further any additional data related to this manuscript will be available upon request from the corresponding author.

\section{Declarations}

\section{Competing interests}

The authors declare no competing financial interest.

\section{Author details}

${ }^{1}$ Calgary Prion Research Unit, Department of Comparative Biology and Experimental Medicine, Faculty of Veterinary Medicine, University of Calgary, 3330 Hospital Drive NW, Calgary, AB T2N 4Z6, Canada. ${ }^{2}$ Hotchkiss Brain Institute, Cumming School of Medicine, University of Calgary, Calgary, AB, Canada. ${ }^{3}$ Department of Medicine - Division of Neurology, Centre for Prions and Protein Folding Diseases, University of Alberta, Edmonton, AB, Canada.

Received: 15 March 2021 Accepted: 17 March 2021

Published online: 01 April 2021

\section{References}

1. Prusiner SB (1982) Novel proteinaceous infectious particles cause scrapie. Science 216:136-144

2. Aguzzi A, Heikenwalder M, Miele G (2004) Progress and problems in the biology, diagnostics, and therapeutics of prion diseases. J Clin Investig 114:153-160

3. Watts JC, Balachandran A, Westaway D (2006) The expanding universe of prion diseases. PLoS Pathog 2:e26

4. Chen CC, Wang YH (2014) Estimation of the exposure of the UK population to the bovine spongiform encephalopathy agent through dietary intake during the period 1980 to 1996. PLoS ONE 9:e94020

5. Hannaoui S, Arifin MI, Chang SC et al (2020) Cellulose ether treatment in vivo generates chronic wasting disease prions with reduced protease resistance and delayed disease progression. J Neurochem 152:727-740

6. Prusiner SB (1989) Scrapie prions. Annu Rev Microbiol 43:345-374

7. Bueler H, Fischer M, Lang Y et al (1992) Normal development and behaviour of mice lacking the neuronal cell-surface PrP protein. Nature 356:577-582

8. Caughey B (2003) Prion protein conversions: insight into mechanisms, TSE transmission barriers and strains. Br Med Bull 66:109-120

9. Baron GS, Wehrly K, Dorward DW, Chesebro B, Caughey B (2002) Conversion of raft associated prion protein to the protease-resistant state requires insertion of PrP-res (PrPSC) into contiguous membranes. EMBO J 21:1031-1040

10. Taraboulos A, Scott M, Semenov A, Avrahami D, Laszlo L, Prusiner SB (1995) Cholesterol depletion and modification of $\mathrm{COOH}$ terminal targeting sequence of the prion protein inhibit formation of the scrapie isoform. J Cell Biol 129:121-132

11. Gilch S, Bach C, Lutzny G, Vorberg I, Schätzl HM (2009) Inhibition of cholesterol recycling impairs cellular PrP(Sc) propagation. Cell Mol Life Sci 66:3979-3991

12. Cui HL, Guo B, Scicluna B et al (2014) Prion infection impairs cholesterol metabolism in neuronal cells. J Biol Chem 289:789-802
13. Hannaoui S, Shim SY, Cheng YC, Corda E, Gilch S (2014) Cholesterol balance in prion diseases and Alzheimer's disease. Viruses 6:4505-4535

14. Perrier V, Imberdis T, Lafon P et al (2017) Plasma cholesterol level determines in vivo prion propagation. J Lipid Res 58:1950-1961

15. Bjorkhem I, Meaney S (2004) Brain cholesterol: long secret life behind a barrier. Arterioscler Thromb Vasc Biol 24:806-815

16. Vance JE (2012) Dysregulation of cholesterol balance in the brain: contribution to neurodegenerative diseases. Dis Models Mech 5:746-755

17. Kacher R, Lamazière A, Heck N et al (2019) CYP46A1 gene therapy deciphers the role of brain cholesterol metabolism in Huntington's disease. Brain 142:2432-2450

18. Nóbrega C, Mendonça L, Marcelo A et al (2019) Restoring brain cholesterol turnover improves autophagy and has therapeutic potential in mouse models of spinocerebellar ataxia. Acta Neuropathol 138:837-858

19. Mitroi DN, Pereyra-Gómez G, Soto-Huelin B et al (2019) NPC1 enables cholesterol mobilization during long-term potentiation that can be restored in Niemann-Pick disease type $\mathrm{C}$ by CYP46A1 activation. EMBO Rep 20:e48143

20. Djelti F, Braudeau J, Hudry E et al (2015) CYP46A1 inhibition, brain cholesterol accumulation and neurodegeneration pave the way for Alzheimer's disease. Brain 138:2383-2398

21. Petrov AM, Pikuleva IA (2019) Cholesterol 24-hydroxylation by CYP46A1: benefits of modulation for brain diseases. Neurotherapeutics 16:635-648

22. Prior M, Lehmann S, Sy MS, Molloy B, McMahon HE (2007) Cyclodextrins inhibit replication of scrapie prion protein in cell culture. J Virol 81:11195-11207

23. Gilch S, Kehler C, Schätzl HM (2006) The prion protein requires cholesterol for cell surface localization. Mol Cell Neurosci 31:346-353

24. Bach C, Gilch S, Rost R et al (2009) Prion-induced activation of cholesterogenic gene expression by Srebp2 in neuronal cells. J Biol Chem 284:31260-31269

25. Brown AR, Rebus S, McKimmie CS, Robertson K, Williams A, Fazakerley JK (2006) Gene expression profiling of the preclinical scrapie-infected hippocampus. Biochem Biophys Res Commun 334:86-95

26. Kotti TJ, Ramirez DM, Pfeiffer BE, Huber KM, Russell DW (2006) Brain cholesterol turnover required for geranylgeraniol production and learning in mice. Proc Natl Acad Sci USA 103:3869-3874

27. Bjorkhem I, Lütjohann D, Diczfalusy U, Ståhle L, Ahlborg G, Wahren J (1998) Cholesterol homeostasis in human brain: turnover of 24S-hydroxycholesterol and evidence for a cerebral origin of most of this oxysterol in the circulation. J Lipid Res 39:1594-1600

28. Lund EG, Guileyardo JM, Russell DW (1998) CDNA cloning of cholesterol 24-hydroxylase, a mediator of cholesterol homeostasis in the brain. Proc Natl Acad Sci USA 96:7238-7243

29. Meaney S, Hassan M, Sakinis A et al (2001) Evidence that major oxysterols in human circulation originate from distinct pools of cholesterol: a stable isotope study. J Lipid Res 42:70-78

30. Noguchi N, Urano Y, Takabe W, Saito Y (2015) New aspects of 24(S)hydroxycholesterol in modulating neuronal cell death. Free Radic Biol Med 87:366-372

31. Liang Y, Lin S, Beyer TP et al (2004) A liver X receptor and retinoid X receptor heterodimer mediates apolipoprotein E expression, secretion and cholesterol homeostasis in astrocytes. J Neurochem 88:623-634

32. Lutjohann D, Breuer O, Ahlborg G et al (1996) Cholesterol homeostasis in human brain: evidence for an age-dependent flux of 24S-hydroxycholesterol from the brain into the circulation. Proc Natl Acad Sci USA 93:9799-9804

33. Xie C, Lund EG, Turley SD, Russell DW, Dietschy JM (2003) Quantitation of two pathways for cholesterol excretion from the brain in normal mice and mice with neurodegeneration. J Lipid Res 44:1780-1789

34. Stefanik M, Valdes JJ, Ezebuo FC et al (2020) FDA-approved drugs efavirenz, tipranavir, and dasabuvir inhibit replication of multiple flaviviruses in vero cells. Microorganisms 8:599. https://doi.org/10.3390/microorgan isms 8040599

35. Rakhmaninaa NY, Vanden AJN (2010) Efavirenz in the therapy of HIV infection. Expert Opin Drug Metab Toxicol 6:95-103

36. Anderson KW, Mast N, Hudgens V et al (2016) Mapping of the allosteric site in cholesterol hydroxylase CYP46A1 for efavirenz, a drug that stimulates enzyme activity. J Biol Chem 291:11876-11886

37. Mast N, White MA, Bjorkhem I et al (2008) Crystal structures of substrate-bound and substrate-free cytochrome P450 46A1, the 
principal cholesterol hydroxylase in the brain. Proc Natl Acad Sci USA 105:9546-9955

38. Mast N, Li Y, Linger M, Clark M, Wiseman J, Pikuleva IA (2014) Pharmacologic stimulation of cytochrome P450 46A1 and cerebral cholesterol turnover in mice. J Biol Chem 289:3529-3538

39. Mast N, Anderson KW, Johnson KM et al (2017) In vitro cytochrome P450 46A1 (CYP46A1) activation by neuroactive compounds. J Biol Chem 292:12934-12946

40. Mast N, Saadane A, Valencia-Olvera A et al (2017) Cholesterol-metabolizing enzyme cytochrome P450 46A1 as a pharmacologic target for Alzheimer's disease. Neuropharmacology 123:465-476

41. Han M, Wang S, Yang N et al (2020) Therapeutic implications of altered cholesterol homeostasis mediated by loss of CYP46A1 in human glioblastoma. EMBO Mol Med 12:e10924

42. Ertmer A, Gilch S, Yun SW et al (2004) The tyrosine kinase inhibitor STI571 induces cellular clearance of PrPSc in prion-infected cells. J Biol Chem 279:41918-41927

43. Gilch S, Winklhofer KF, Groschup MH et al (2001) Intracellular re-routing of prion protein prevents propagation of PrPSC and delays onset of prion disease. EMBO J 20:3957-3966

44. Scott M, Groth D, Foster D et al (1993) Propagation of prions with artificial properties in transgenic mice expressing chimeric PrP genes. Cell 73:979-988

45. Sukhvir SP, Baker CA, Demczyk CA, Smith EW, Julius C, Weissmann C (2007) Prion strain discrimination in cell culture: the cell panel assay. Proc Natl Acad Sci USA 104:20908-20913

46. Hannaoui S, Amidian S, Cheng YC et al (2017) Destabilizing polymorphism in cervid prion protein hydrophobic core determines prion conformation and conversion efficiency. PLoS Pathog 13:e1006553

47. Shim SY, Karri S, Law S, Schatzl HM, Gilch S (2016) Prion infection impairs lysosomal degradation capacity by interfering with rab7 membrane attachment in neuronal cells. Sci Rep 11:21658. https://doi.org/10.1038/ srep21658

48. Bartoletti-Stella A, Corrado P, Mometto N et al (2019) Analysis of RNA expression profiles identifies dysregulated vesicle trafficking pathways in Creutzfeldt-Jakob disease. Mol Neurobiol 56:5009-5024

49. Jones $E$, Hummerich $H$, Viré $E$ et al (2020) Identification of novel risk loci and causal insights for sporadic Creutzfeldt-Jakob disease: a genomewide association study. Lancet Neurol 19:840-848

50. Russell DW, Halford RW, Ramirez DM, Shah R, Kotti T (2009) Cholesterol 24-hydroxylase: an enzyme of cholesterol turnover in the brain. Annu Rev Biochem 78:1017-1040
51. Yutuc E, Angelini R, Baumert M et al (2020) Localization of sterols and oxysterols in mouse brain reveals distinct spatial cholesterol metabolism. Proc Natl Acad Sci USA 117:5749-5760

52. Ramirez DM, Andersson S, Russell DW (2008) Neuronal expression and subcellular localization of cholesterol 24-hydroxylase in the mouse brain. J Comp Neurol 507:1676-1693

53. Moutinho M, Nunes MJ, Rodrigues E (2016) Cholesterol 24-hydroxylase: brain cholesterol metabolism and beyond. Biochem Biophys Acta 1861:1911-1920

54. Ohyama Y, Meaney S, Heverin M (2006) Studies on the transcriptional regulation of cholesterol 24-hydroxylase (CYP46A1): marked insensitivity toward different regulatory axes. J Biol Chem 281:3810-3820

55. Mangé A, Nishida N, Milhavet $\mathrm{O}, \mathrm{McM}$ ahon HE, Casanova D, Lehmann S (2000) Amphotericin B inhibits the generation of the scrapie isoform of the prion protein in infected cultures. J Virol 74:3135-3140

56. Simons K, Ehehalt R (2002) Cholesterol, lipid rafts, and disease. J Clin Invest 110:597-603

57. Petrov AM, Mast N, LiY, Denker J, Pikuleva IA (2020) Brain sterol flux mediated by cytochrome P450 46A1 affects membrane properties and membrane-dependent processes. Brain Commun 20:fcaa043

58. Kant RV, Langness VF, Herrera CM et al (2019) Cholesterol metabolism is a druggable axis that independently regulates tau and amyloid-beta in PSC-derived Alzheimer's disease neurons. Cell Stem Cell 24: 363-375 e369

59. Apostolova N, Blas-Garcia A, Galindo MJ, Esplugues JV (2017) Efavirenz: what is known about the cellular mechanisms responsible for its adverse effects. Eur J Pharmacol 812:163-173

60. Takada LT, Geschwind MD (2013) Prion diseases. Semin Neurol 33:348-356

61. Carroll JA, Race B, Phillips K, Striebel JF, Chesebro B (2017) Statins are ineffective at reducing neuroinflammation or prolonging survival in scrapie-infected mice. J Gen Virol 98:2190-2199

\section{Publisher's Note}

Springer Nature remains neutral with regard to jurisdictional claims in published maps and institutional affiliations.
Ready to submit your research? Choose BMC and benefit from:

- fast, convenient online submission

- thorough peer review by experienced researchers in your field

- rapid publication on acceptance

- support for research data, including large and complex data types

- gold Open Access which fosters wider collaboration and increased citations

- maximum visibility for your research: over $100 \mathrm{M}$ website views per year

At BMC, research is always in progress.

Learn more biomedcentral.com/submissions 